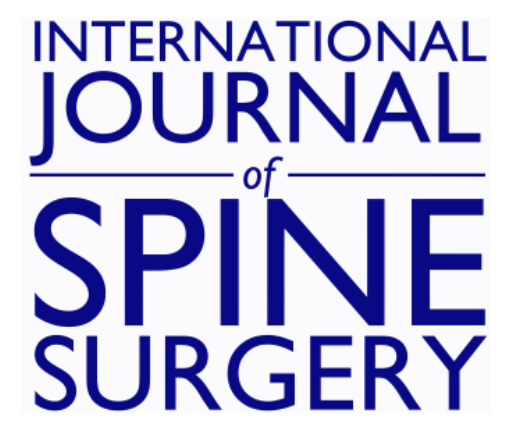

\title{
A Survey On Spine Surgeons' Opinions On The Release Of The Centers for Medicare and Medicaid Services Data
}

John D. Koerner, Gregory D. Schroeder, Anuj Shah, Paul M. Arnold, Robert E. Isaacs, Alan S. Hilibrand, Alexander R. Vaccaro and Kristen E. Radcliff

Int J Spine Surg 2015, 9 ()

doi: https://doi.org/10.14444/2051

http://ijssurgery.com/content/9/51

This information is current as of April 26, 2023.

Email Alerts Receive free email-alerts when new articles cite this article. Sign up at:

http://ijssurgery.com/alerts

The International Journal of Soing Surgerih http://ijssurgery.com/ by guest on April 26, 2 2397 Waterbury Circle, Suite 1,

Aurora, IL 60504, Phone: +1-630-375-1432 


\section{A Survey On Spine Surgeons' Opinions On The Release Of The Centers for Medicare and Medicaid Services Data}

John D. Koerner MD, ${ }^{1}$ Gregory D. Schroeder MD, ${ }^{1}$ Anuj Shah BS, ${ }^{2}$ Paul M. Arnold MD, ${ }^{3}$ Robert E. Isaacs MD, 4 Alan S. Hilibrand MD, ${ }^{1}$ Alexander $R$. Vaccaro $M D$, PhD, ${ }^{1}$ Kristen E. Radcliff $M D^{1}$

${ }^{1}$ The Rothman Institute at Thomas Jefferson University, Philadelphia, PA, 2Thomas Jefferson University, Philadelphia, PA, ${ }^{3}$ Department of Neurosurgery, The University of Kansas, Kansas City, KS, ${ }^{4}$ Duke University, Durham, $N C$

\section{Abstract}

Background

In April 2014 the Centers for Medicare and Medicaid Services (CMS) released a dataset for the public which included information on services provided by physicians and healthcare providers for Medicare beneficiaries in the 2012 calendar year. The objective of this study is to determine spine surgeons' opinions on the release of the CMS data, and determine how they feel this information may affect patient care.

\section{Methods}

A survey was sent to members of the Association for Collaborative Spine Research (ACSR) regarding their practice patterns and opinions on the release of the CMS data. Determinants included surgical subspecialty, practice setting, years in practice and region. The average response was collected for each question and compared across groups. Additionally, questions in which greater than $75 \%$ of respondents either agreed (agree or strongly agree) or disagreed (disagree or strongly disagree) were identified.

\section{Results}

Seventy-six surgeons completed the survey, and while the overall interobserver reliability between each question was only slight $(\kappa=0.11)$, more than $75 \%$ of respondents either agreed or strongly agreed with five statements and, more than $75 \%$ of respondents either disagreed or strongly disagreed with six statements. While $86 \%$ of surgeons are in favor of more transparency, $83 \%$ of respondents felt that without the proper context, the data released does not accurately portray spine surgery. Additionally, $96 \%$ of spine surgeons do not believe the CMS data helps patients decide which spine surgeon is best for them.

\section{Conclusions}

The small percentage of spine surgeons who responded to this survey are in favor of more transparency but do not feel the release of the CMS data either accurately represents spine surgeons or will help patients better identify the appropriate surgeon. In spite of these concerns, it is unlikely the release of the CMS data will significantly impact the accessibility of a spine surgeon to a Medicare beneficiary.

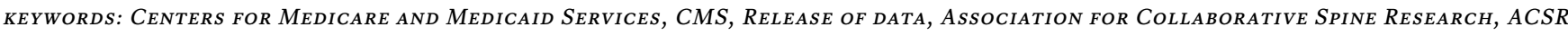
VOLUME 9 ARTICLE 51 DOI: 10.14444/2051

\section{Introduction}

In April 2014, the Centers for Medicare and Medicaid Services (CMS) released a dataset for the public which included information on services provided by physicians and healthcare providers for Medicare beneficiaries in the 2012 calendar year (http://www.cms.gov/Research-Statistics-Data-andSystems/Statistics-Trend...). According to the CMS, the purpose of the release was to "make our healthcare system more transparent, affordable, and ac- countable." ${ }^{1}$ However, as noted on the Medicare website, this data may not be entirely representative of a physician's practice, as only Medicare beneficiaries are included. ${ }^{1}$ The data is supplied in Microsoft Excel (Microsoft Corporation, Redmond, WA) spreadsheets, as well as a searchable database which includes the description of service, number of services provided, number of Medicare Beneficiaries, the average Medicare allowed amount, the average submitted charge amount, and the average Medicare payment amount. This financial data had previously 
been private information.

Numerous other sources have since utilized the data to create their own searchable databases, which take additional steps by calculating the total payment amounts to physicians. Multiple publications in the lay media resulted from the CMS data, including articles on the apparent small fraction of doctors who receive a large proportion of the Medicare payments and lists of "Best-Paid" doctors. ${ }^{2}$ Additionally, the New York Times identified multiple pitfalls in the interpretation of the released data, including that is does not take overhead or salaried employees into account; it does not correctly allocate money that is shared between physician, and it does not account for the complexity of patients treated. ${ }^{3}$ Failure of patients to understand the limitations of this published data can leave patients with a drastically altered view of different physicians. ${ }^{4}$

While improved transparency may provide patients with information to help decide which physician is best for them, how the current data will affect patient care is still unclear. The purpose of this study is to determine spine surgeons' opinions on the release of the CMS data, and determine how they feel this information may affect patient care.

\section{Methods}

A survey was sent to members of the Association for Collaborative Spine Research (ACSR) regarding their practice patterns and opinions on the release of the CMS data. An in-person paper version was administered at the annual meeting, as well as an online version to members not at the meeting. Determinants included surgical subspecialty, practice setting, years in practice and region. Agreement or disagreement to statements was graded based on the following scale: strongly disagree, disagree, neutral, agree, and strongly agree. The average response was collected for each question and compared across groups. Additionally, questions in which greater than $75 \%$ of respondents either agreed (agree or strongly agree) or disagreed (disagree or strongly disagree) were identified.

\section{Statistical Methods}

A Kappa coefficient ( $\kappa$ ) was used to assess the interobserver reliability of the respondents and was interpreted with the Landis and Koch grading system. ${ }^{5}$ This system defines slight agreement as a $\kappa$ of less than 0.2 , fair agreement as a $\kappa$ between 0.4 and 0.6 , substantial agreement as a $\kappa$ between 0.6 and 0.8 , and excellent agreement if the $\kappa$ is greater than 0.8 . Cochran's Q test was also used to identify whether responses had statistically distinct response rates based on the surgeons' subspecialty, practice setting, years in practice or region. All statistical analyses were carried out in the statistical platform R 3.1.1 (R Foundation for Statistical Computing, Vienna Austria).

\section{Results}

A total of 353 surveys were sent out, and 76 surveys (21.5\%) were completed; the demographics of the surgeons can be found in Table 1 . All but three surgeons (95.7\%) accept Medicare, and Table 2 demonstrates an estimate of the percentage of a spine surgeon's patients that are Medicare beneficiaries, and an estimate of the percentage of a spine surgeon's salary that comes from Medicare.

The average response ( 1 - strongly disagree; 2-disagree; 3-neutral; 4-agree; 5-strongly agree) for all questions is reported in Table 3 , and while the overall intrerobserver reliability was only slight $(\kappa=0.11)$, more than $75 \%$ of respondents agreed or strongly agreed with five statements (Table 4), and more than $75 \%$ of respondents disagreed or strongly disagreed with six statements (Table 5). In the final question, surgeons were asked to identify all reasons they believe CMS released the financial data, and a significant $(\mathrm{p}<0.001)$ percentage of surgeons $(68.1 \%)$ believe identifying outliers abusing the system was one of the major reasons for the release of the CMS data (Figure 1).

Regression analysis was performed to determine if surgeon subspecialty, practice setting, years in practice or region affected the responses, but none were found to be statistically significant. 
Table 1. Demographics of Respondents.

\begin{tabular}{|c|c|}
\hline Specialty & Count $(\%)$ \\
\hline Neurosurgery & $21(30.0 \%)$ \\
\hline Orthopaedic Surgery & $49(70.0 \%)$ \\
\hline \multicolumn{2}{|l|}{ Practice Setting } \\
\hline Academic & $44(62.9 \%)$ \\
\hline Private Practice / Hybrid & $26(37.1 \%)$ \\
\hline \multicolumn{2}{|l|}{ Years in Practice } \\
\hline $0-5 \mathrm{yrs}$ & $16(22 / 9 \%)$ \\
\hline $5-10 \mathrm{yrs}$ & $14(20.0 \%)$ \\
\hline $11-15 \mathrm{yrs}$ & $11(15.7 \%)$ \\
\hline $15+\mathrm{yrs}$ & $29(41.4 \%)$ \\
\hline \multicolumn{2}{|l|}{ Region } \\
\hline Northeast & $22(34.9 \%)$ \\
\hline Midwest & $9(14.3 \%)$ \\
\hline South & $22(34.9 \%)$ \\
\hline Southwest & $10(15.9 \%)$ \\
\hline Mountain West & $5(7.9 \%)$ \\
\hline West Coast & $6(9.5 \%)$ \\
\hline
\end{tabular}

Table 2. An estimate of the percent of patients in the surgeons' practice that are Medicare beneficiaries, and an estimate of the percent of the surgeons' salary that comes from Medicare.

\begin{tabular}{|l|r|}
\hline $\begin{array}{l}\text { Estimated \% of patients in your practice who are Medicare } \\
\text { beneficiaries }\end{array}$ & \\
\hline $0-25 \%$ & $\begin{array}{r}19 \\
(27.1 \%)\end{array}$ \\
\hline $26-50 \%$ & 42 \\
& $(60.0 \%)$ \\
\hline $51-75 \%$ & $6(8.6 \%)$ \\
\hline $75-100 \%$ & $3(4.3 \%)$ \\
\hline Estimated \% of your salary from Medicare & \\
\hline $0-25 \%$ & $(51.4 \%)$ \\
\hline $26-50 \%$ & 27 \\
\hline $51-75 \%$ & $(38.6 \%)$ \\
\hline $75-100 \%$ & $3(4.3 \%)$ \\
\hline
\end{tabular}

\section{Discussion}

The goal of this project was to determine spine surgeons' opinions on the release of the CMS data, and determine how they feel this information may affect patient care. We identified a broad consensus that the release of this data will not help patients choose the best spine surgeon for them, with $95.7 \%$ of spine surgeons disagreeing with the statement: "The CMS data will help patients decide which spine surgeon is best for them." Furthermore, $86.2 \%$ of surgeons disagreed that the data released will help patients identify surgeons with appropriate indications.

While spine surgeons' felt the current methods for the release of financial data will have little benefit to patients, this is not because they are opposed to more transparency in healthcare. Over $86 \%$ of respondents are in favor of more transparency, but they feel the manor in which the data was released does not accurately portray spine surgery. Approximately $43 \%$ all Medicare payments are used to pay for fixed overhead, and an additional $9 \%$ will go to medical malpractice insurance for spine surgeons. ${ }^{4}$ Furthermore, the average medical student graduates with almost $\$ 200,000$ in student loans that continue to accrue interests during the 6-8 years required to become a spine surgeon, ${ }^{6}$ and the opportunity cost associated with the decision to become a spine surgeon is even more substantial. Because the CMS data lacks the proper context, $83 \%$ of respondents felt the financial data does not accurately portray spine surgery.

Another limitation of the CMS data is the inability of the patient to determine the overall practice trends of a physician. This could result in two different scenarios for patients attempting to use the data: if the physician's practice does not include many Medicare

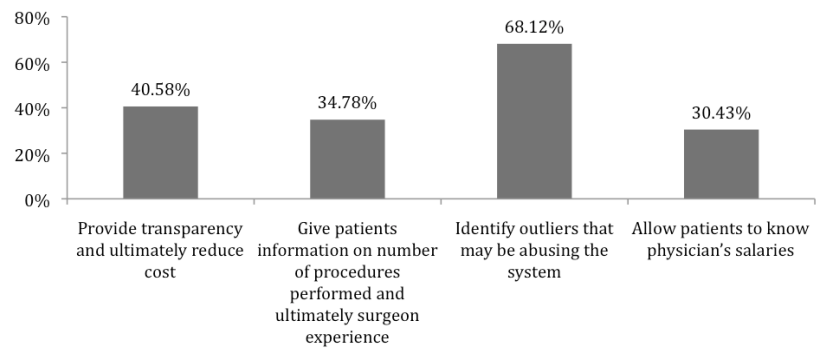

Fig. 1. Graph illustrating the reasons surgeons believe CMS released the data. 
patients, patients may believe that the surgeon is not busy or experienced due to low volume; on the other hand, if a surgeon's practice consists of a large proportion of Medicare patients, or the surgeon practices at a large referral center taking care of complex pathology, the surgeons may be viewed as overly aggressive with potentially inappropriate indications for surgery. Either scenario may not be accurate, but

Table 3. Overall results from the survey. (1 - strongly disagree; 2-disagree; 3-neutral; 4-agree; 5-strongly agree).

\begin{tabular}{|c|c|}
\hline Survey Questions & $\begin{array}{r}\text { Average } \\
\text { Answer }\end{array}$ \\
\hline $\begin{array}{l}\text { The intentions of the CMS to make our healthcare system more } \\
\text { transparent, affordable, and accountable were fulfilled by the } \\
\text { release of this information. }\end{array}$ & 2.2 \\
\hline $\begin{array}{l}\text { The CMS data will help patients decide which spine surgeon is } \\
\text { best for them. }\end{array}$ & 1.7 \\
\hline $\begin{array}{l}\text { The availability of this data will help patients identify surgeons } \\
\text { with inappropriate indications. }\end{array}$ & 2.0 \\
\hline Ultimately, the release of this data is beneficial for patients. & 2.2 \\
\hline Articles in the press presented this data in an accurate way. & 2.0 \\
\hline $\begin{array}{l}\text { The CMS data accurately portrays the distribution of cases I } \\
\text { typically perform throughout my practice (including non-Medicare } \\
\text { patients). }\end{array}$ & 2.1 \\
\hline $\begin{array}{l}\text { The data specific to spine fusion and rates of cases performed } \\
\text { accurately portrays my practice. }\end{array}$ & 2.1 \\
\hline $\begin{array}{l}\text { It is important for patients to know the number of spine fusions I } \\
\text { perform on Medicare patients each year. }\end{array}$ & 2.3 \\
\hline $\begin{array}{l}\text { It is important for patients to know the percent of Medicare } \\
\text { patients I end up performing a spinal fusion on. }\end{array}$ & 2.1 \\
\hline $\begin{array}{l}\text { The data would be more beneficial if patients knew the percentage } \\
\text { of Medicare patients that make up my practice. }\end{array}$ & 3.3 \\
\hline $\begin{array}{l}\text { The Spinal Fusion database will help authorities identify and } \\
\text { investigate surgeons with inappropriate indications. }\end{array}$ & 2.5 \\
\hline $\begin{array}{l}\text { Because these databases only include Medicare patients, people } \\
\text { may be mislead into believing a surgeon is inexperienced if they } \\
\text { do not treat many Medicare patients. }\end{array}$ & 3.7 \\
\hline $\begin{array}{l}\text { This data portrays physicians who treat a high percentage of } \\
\text { Medicare patients in a negative way. }\end{array}$ & 3.8 \\
\hline $\begin{array}{l}\text { The release of this data will discourage me from treating Medicare } \\
\text { patients in the future. }\end{array}$ & 3.3 \\
\hline $\begin{array}{l}\text { Despite the limited compensation I ultimately receive from treating } \\
\text { Medicare patients, I feel a moral obligation to treat these patients. }\end{array}$ & 4.0 \\
\hline $\begin{array}{l}\text { If I treat more Medicare patients, it is likely I will be investigated } \\
\text { by CMS. }\end{array}$ & 3.3 \\
\hline $\begin{array}{l}\text { I have stopped treating Medicare patients because of the release of } \\
\text { this data. }\end{array}$ & 1.9 \\
\hline $\begin{array}{l}\text { I will be more conservative in surgical indications for Medicare } \\
\text { patients in the future because of this data release. }\end{array}$ & 2.5 \\
\hline $\begin{array}{l}\text { These reports more accurately portrayed Spine Surgeons than } \\
\text { physicians in other fields. }\end{array}$ & 2.2 \\
\hline The release of this data is a violation of my privacy. & 3.2 \\
\hline $\begin{array}{l}\text { This information will influence medical students when choosing } \\
\text { specialties. }\end{array}$ & 2.8 \\
\hline $\begin{array}{l}\text { Publication of individual surgeon complication rates would be } \\
\text { more valuable to patients than billing data. }\end{array}$ & 3.0 \\
\hline $\begin{array}{l}\text { Physicians at tertiary referral centers will be viewed as more } \\
\text { aggressive in performing fusion and complex fusion without } \\
\text { information such as comorbidities and percent of cases that are } \\
\text { referred revisions. }\end{array}$ & 4.1 \\
\hline $\begin{array}{l}\text { I am in favor of more transparency in quality and in management } \\
\text { of healthcare costs. }\end{array}$ & 4.1 \\
\hline $\begin{array}{l}\text { The CMS data is driven by the demographics of the respective } \\
\text { patient populations of each surgeon. }\end{array}$ & 3.7 \\
\hline $\begin{array}{l}\text { Without data on long-term cost of care, the CMS data does not } \\
\text { represent spine surgery accurately because there are high initial } \\
\text { expenditures. }\end{array}$ & 4.0 \\
\hline $\begin{array}{l}\text { Because of the complexity of this database, patients are less likely } \\
\text { to use this data, and it is more likely to be used by special interest } \\
\text { groups and malpractice attorneys. }\end{array}$ & 4.2 \\
\hline
\end{tabular}

without the proper context the data may misinform patients. Misinterpretation of the data can easily be seen in the authors' own practice, as the senior surgeons have a spent years developing a referral network that results in an increase in the treatment of younger patients; where as the referrals for the junior partners referrals often come from in hospital consultations of Medicare patients. Because of this, a patient reviewing the Medicare claims data may believe that the older surgeons are significantly less busy than the younger surgeons

Table 4. More than $75 \%$ of respondents agreed or strongly agreed with these five statements.

\begin{tabular}{|l|r|}
\hline $\begin{array}{l}\text { Questions in which }>\text { 75\% of respondents agreed or strongly } \\
\text { agreed }\end{array}$ & $\begin{array}{r}\text { Percent } \\
\text { who } \\
\text { agree or } \\
\text { strongly } \\
\text { agree }\end{array}$ \\
\hline $\begin{array}{l}\text { Despite the limited compensation I ultimately receive from treat- } \\
\text { ing Medicare patients, I feel a moral obligation to treat these pa- } \\
\text { tients. }\end{array}$ & $84.6 \%$ \\
\hline $\begin{array}{l}\text { Physicians at tertiary referral centers will be viewed as more ag- } \\
\text { gressive in performing fusion and complex fusion without infor- } \\
\text { mation such as comorbidities and percent of cases that are re- } \\
\text { ferred revisions. }\end{array}$ & $76.9 \%$ \\
\hline $\begin{array}{l}\text { I am in favor of more transparency in quality and in management } \\
\text { of healthcare costs. }\end{array}$ & $86.2 \%$ \\
\hline $\begin{array}{l}\text { Without data on long-term cost of care, the CMS data does not } \\
\text { represent spine surgery accurately because there are high initial } \\
\text { expenditures. }\end{array}$ & $83.1 \%$ \\
\hline $\begin{array}{l}\text { Because of the complexity of this database, patients are less like- } \\
\text { ly to use this data, and it is more likely to be used by special in- } \\
\text { terest groups and malpractice attorneys }\end{array}$ & $78.5 \%$ \\
\hline
\end{tabular}

Table 5. More than $75 \%$ of respondents disagreed or strongly disagreed with these six statements.

\begin{tabular}{|l|r|}
\hline $\begin{array}{l}\text { Questions in which }>\text { 75\% of respondents disagreed or } \\
\text { strongly disagreed }\end{array}$ & $\begin{array}{r}\text { Percent who } \\
\text { disagree or } \\
\text { strongly dis- } \\
\text { agree }\end{array}$ \\
\hline $\begin{array}{l}\text { The intentions of the CMS to make our healthcare system } \\
\text { more transparent, affordable, and accountable were ful- } \\
\text { filled by the release of this information. }\end{array}$ & $76.8 \%$ \\
\hline $\begin{array}{l}\text { The CMS data will help patients decide which spine sur- } \\
\text { geon is best for them. }\end{array}$ & $95.7 \%$ \\
\hline $\begin{array}{l}\text { The availability of this data will help patients identify sur- } \\
\text { geons with inappropriate indications. }\end{array}$ & $84.1 \%$ \\
\hline Articles in the press presented this data in an accurate way. & $84.1 \%$ \\
\hline $\begin{array}{l}\text { It is important for patients to know the percent of Medicare } \\
\text { patients I end up performing a spinal fusion on. }\end{array}$ & $78.5 \%$ \\
\hline $\begin{array}{l}\text { I have stopped treating Medicare patients because of the re- } \\
\text { lease of this data. }\end{array}$ & $95.3 \%$ \\
\hline
\end{tabular}


On top of the concern that surgeons have for patients misinterpreting the data, $84.1 \%$ of surgeons believe the articles in the press do not present the data in an accurate way. One such example of this is when CBS News used the new data to identify surgeons performing a significant number of "controversial back surgeries," and published a report on lumbar fusions. ${ }^{7}$ While few would argue that a lumbar fusion for isolated discogenic back pain is controversial, the report fails to discuss the many evidence-based reasons to perform a lumbar fusion. ${ }^{8,9}$ The effectiveness, and cost-effectiveness of a lumbar fusion for degenerative spondylolisthesis has been well documented by classic studies ${ }^{10,11}$ and by the Spine Patient Outcomes Research Trial (SPORT), ${ }^{8,9}$ but rather than discussing appropriate indications for a lumbar fusion, the article attempts to scare viewers about the dangers of the procedure.

In spite of the concerns that surgeons have with the release of the CMS data, it does not appear that the decision to release this data will jeopardize the access Medicare beneficiaries have to spine surgeons. Over $84 \%$ of spine surgeons reported a moral obligation to treat these patients, and $95 \%$ of surgeons disagreed with the statement: "I have stopped treating Medicare patients because of the release of this data."

Limitations to this study exist, including that it is a survey of a small number of surgeons, of which a disproportionate number work in an academic institution. No statistical verification that either the 353 members of the ACSR was a representative subset of all spine surgeons or that the $21.5 \%$ of the ACRS members who chose to complete and return this questioner was a representative subset of the members of the ACSR. Thus, severe sampling bias could be contained in the results of this study and the results presented may not accurately reflect the opinions spine surgeons in general. The results presented here are the opinions of 76 academically oriented spine surgeons, and it is possible that these surgeons may have considerably different views from the rest of the spine surgeons; however while undoubtedly the respondents of this survey are more academic than the average spine surgeon, there is significant diversity in the respondents, as they are from all over the country, differing specialties and differing experience. Nonetheless, the results of this survey may not be representative of all spine surgeons. Furthermore, the overall agreement was only slight $(\kappa=0.11)$, so while there was substantial consensus on 11 questions, it is difficult to interpret the results of the other questions.

A further limitation to this study is that it reports the opinions of spine surgeons not of patients. While this allowed us to accomplish one of the major goals of the study, which was to determine if the release of the CMS data would affect accessibility of a spine surgeon to a Medicare beneficiary, it does not determine if patients had an understanding of, or ability to, interpret the released data, or if the data released affective patient selection of a surgeon.

\section{Conclusion}

Spine surgeons are in favor of more transparency in healthcare, but they do not feel the release of the CMS data will help patients better identify the appropriate surgeon to treat their spinal pathology. Similarly, they feel that without appropriate context, the released data fails to accurately represent spine surgeons. In spite of the concerns spine surgeons have about the release of the CMS data, it is unlikely that the release of data will significantly impact the accessibility of a spine surgeon to a Medicare beneficiary.

\section{References}

1. Medicare Provider Utilization and Payment Data: Physician and Other Supplier. 2014; http://www.cms.gov/Research-Statistics-Data-andSystems/Statistics-Trend.... Accessed October 24, 2014.

2. Abelson R, Cohen S. Sliver of Medicare Doctors Get Big Share of Payouts. The New York Times. 4/9/ 14, 2014.

3. Grady D, FInk S. The Medicare Data's Pitfalls. The New York Times. 4/10/14, 2014.

4. Keating D, Rivero C, Downs K, Chow E. How much Medicare pays doctors. The Washington Post. 4/9/14, 2014. 
5. Landis JR, Koch GG. The measurement of observer agreement for categorical data. Biometrics. Mar 1977;33(1):159-174.

6. Medical Student Education: Debt, Costs, and Loan Repayment Fact Card. 2014; https://www.aamc.org/download/152968/data/ debtfactcard.pdf. Accessed 10/24, 2014.

7. Tapping into controversial back surgeries. 2014; http://www.cbsnews.com/news/tapping-intocontroversial-back-surgeries/. Accessed October 24, 2014.

8. Weinstein JN, Lurie JD, Tosteson TD, et al. Surgical compared with nonoperative treatment for lumbar degenerative spondylolisthesis. four-year results in the Spine Patient Outcomes Research Trial (SPORT) randomized and observational cohorts. $J$ Bone Joint Surg Am. Jun 2009;91(6):1295-1304.

9. Tosteson AN, Lurie JD, Tosteson TD, et al. Surgical treatment of spinal stenosis with and without degenerative spondylolisthesis: cost-effectiveness after 2 years. Ann Intern Med. Dec 16 2008;149(12):845-853.

10. Herkowitz HN, Kurz LT. Degenerative lumbar spondylolisthesis with spinal stenosis. A prospective study comparing decompression with decompression and intertransverse process arthrodesis. J Bone Joint Surg Am. Jul 1991;73(6):802-808.

11. Kornblum MB, Fischgrund JS, Herkowitz HN, Abraham DA, Berkower DL, Ditkoff JS. Degenerative lumbar spondylolisthesis with spinal stenosis: a prospective long-term study comparing fusion and pseudarthrosis. Spine (Phila Pa 1976). Apr 1 2004;29(7):726-733; discussion 733-724.

\section{Disclosures}

This work was supported by The Association for Collaborative Spine Research. Gregory Schroeder has received funding from Medtronic for travel to meetings. John Koerner has received research support from Medtronic. Paul Arnold has acted as consultant for Medtronic, Stryker, FizoMed, AOSpine, Life Spine, Intgra Life, Spine Wave, MIEMS, Cerapedics and has stocks in Zplasty. Robert Isaacs is on the board of Saferay Spine; has acted as consultant for NuVasive, Baxano, Vertera; has received grants and royalties from NuVasive; has stocks in Providence, Saferay Spine, SafeWire, Vertera, Vilaspine; has received travel compensation from Verter and the ACSR and has acted as scientific advisor to Vertera. Alan Hilibrand has received royalties from Aesculap/B.Braun, Amedica, Biomet, and Stryker, and owns stocks in Amedica, Benvenue Medical, Lifespine, Nexgen, Paradigm Spine, PSD, Spinal Ventures, and Vertiflex. Alex Vaccaro has acted as consultant for Medtronic, Stryker, Globus, Stout, Gerson Lehrman Group, Guidepoint Global, Medacorp, Innovative Surgical Design, Orthobullets, has performed expert testimony for Ellipse; serves on advisory boards or committees for Innovative Surgical Design, and Spinicity; has received royalties from Thieme, Jaypee, Elsevier, Taylor Francis, Aesculap, Globus, Medtronic, Stryker, DePuy; has received institutional support from Cerapedics; owns stocks in Spine Medica, Computational Biodynamics, Progressive Spinal Technologies, Spinology, Small Bone Innovations, Cross Current, In Vivo, Flagship Surgical, Advanced Spinal Intellectual Properties, Cytonics, Bonovo Orthopaedics, Electrocore, Gamma Spine, Location Based Intelligence, FlowPharma, R.S.I., Replication Medica, Globus, Stout Medical, Rothman Institute and Related Properties, Innovative Surgical Design, and Spinicity. Kris Radcliff has consulted for Depuy, Medtronic, LDR Spine, Globus; received grants from DePuy, Medtronic, Paradigm Spine; received royalties from Globus; and has been given travel support by Globus, AOSpine, Stryker, DePuy.

\section{Corresponding Author}

Greg Schroeder, The Rothman Institute, 925 Chestnut Street, 5th floor, Philadelphia, PA 19107.

gregdschroeder@gmail.com.

Published 13 October 2015.

This manuscript is generously published free of charge by ISASS, the International Society for the Advancement of Spine Surgery. Copyright @ 2015 ISASS. To see more or order reprints or permissions, see http://ijssurgery.com. 